\title{
Metal implants and MRI: A mythbuster study
}

\author{
Zoltán Csernátony ${ }^{1}$, Lei Zhang ${ }^{1 *}$, Kristóf Takács ${ }^{2}$, Loránd Csámer ${ }^{3}$, Ágnes Éva Kovács ${ }^{3}$ and Sándor Manó ${ }^{3}$ \\ ${ }^{1}$ Department of Orthopaedic Surgery, Faculty of Medicine, University of Debrecen, Hungary \\ ${ }^{2}$ Faculty of Medicine, University of Debrecen, Hungary \\ ${ }^{3}$ Laboratory of Biomechanics, Department of Orthopaedic Surgery, Faculty of Medicine, University of Debrecen, Hungary
}

\begin{abstract} contraindication. In this article we aimed to provide evidence for this controversial point of view. as the displacement. position change were observed. for those patients with orthopedic-traumatological metal implants.

\section{Introduction}

The increasing success of sports medicine largely depends on the modern implant technique development. In both traumatological and elective orthopedic surgeries, better and better metal implants are designed and applied. Even in Hungary such a small country, thousands of bone and joint surgeries with metal prostheses were performed every month. However, while patients benefit from the modern technique, they may have to face other problems as well. For example, they may not be allowed to take the MRI examination. Even though many authors have reported on this topic [1-5], the results obtained are various. Due to the strong magnetic field during the MRI exam, there is still concern related to movement, heating or artefacts that may present problems. In this article we aim to investigate the temperature and position change under different conditions during $1.5 \mathrm{~T} / 3 \mathrm{~T}$ MRI scanning for regular orthopedic implants.
\end{abstract}

Metal implants have been widely used in traumatological and elective orthopedic surgeries. However, for the MRI examination, with metal implants is believed be a

13 different metal orthopedic implants were included in this study and all of them were tested by both 1.5T and 3T MRI machine. Each implant was also tested in dry and wet (soaked with saline) different humidity conditions. The scanning time was 27 min and the main outcomes were the surface temperature change as well

The results showed that regardless of whether the implant is dry or wet, regardless of the strength of the scanning magnetic field, no significant temperature and

As for the concern that MRI exam may cause implant instability and heat problems, we have proved it is a misconception. The MRI can be performed without risk

\section{Materials and methods \\ Implants}

Thirteen different metal implants were assessed for MR safety and one polyethylene cup was used as control. Figure 1 shows the number of each implant and Table 1 summarizes the details for the implants.

\section{MR scanning sequences}

The following sequence was applied: (1) Lumbar spine T2 (7 min $30 \mathrm{~s}$ ); (2) Lumbar spine T1 (5 min $30 \mathrm{~s}$ ); (3) Lumbar spine STIR (8 min); (4) Hip GRE (6 min). The total scanning time was $27 \mathrm{~min}$. Each implant was assessed in both 1.5T MR system (GE Signa Excite MR, GE Healthcare, Little Chalfont, UK) and 3T MRI system (Philips Achieva, Amsterdam, The Netherlands).

\section{Evaluation of heating and displacement}

All implants stayed in the MR room for at least 2 hours before the scanning. The baseline surface temperature was measured first. Figure 2 shows the polystyrene (Styrofoam) covers designed for each implant to insulate and fix the thermometer probe. Place the implant into the bottom half of the cover, the UNI-T UT320 thermometer probe (UNITREND Group Ltd, Hong Kong, accuracy: $0.1^{\circ} \mathrm{C}$ ) was inserted into the top cover. Press the top half against the bottom to make sure the implant was very well covered and the probe touched the surface of the implant. Then removing the probe, putting the implant and the bottom cover into the MR workspace. The cover's location was also marked before the scanning. After the scanning, first check and measure any displacement from the initial position. Then place the top cover onto each implant to prevent any slight temperature change. Small items were measured first as their temperature change could be more rapidly.

\section{Different implant humidity conditions}

The first series of measurements were performed with dry implants in an air-conditioned environment. Considering the possible surface effect of the water, all measurements were repeated in a humid environment as well. Each implant was immersed in saline and wrap it with wet gauze. After measuring the baseline surface temperature, the implant wrapped in gauze and the bottom cover were placed into the MR workspace. The same scanning parameters and access method was applied as mentioned above.

*Correspondence to: Lei Zhang, 4032 Nagyerdei krt. 98 . Department of Orthopaedic Surgery, University of Debrecen, Hungary, E-mail: zltj2007@gmail.com

Key words: $M R, M R I$, metal implant, temperature rise, displacement, heat

Received: April 20, 2021; Accepted: May 05, 2021; Published: May 07, 2021 
Table 1. Metallic implants included in the study

\begin{tabular}{|c|c|c|c|c|c|c|}
\hline Item No. & Implant type & Volume $\left(\mathrm{cm}^{3}\right)$ & Weight (g) & $\begin{array}{l}\text { Surface } \\
\left(\mathrm{cm}^{2}\right)\end{array}$ & Surface/volume ratio & Material \\
\hline 1 & Traditional split medullary nail $(320 \mathrm{~mm})$ & 15.0 & 102.3 & 188.8 & 12.58 & Steel ISO 5832-1 \\
\hline 2 & Medullary nail $(500 \mathrm{~mm})$ & 21.7 & 191.1 & 370.9 & 17.09 & Steel ISO 5832-1 \\
\hline 3 & Ender nail $(420 \mathrm{~mm})$ & 20.0 & 55.6 & 62.6 & 3.13 & Steel ISO 5832-1 \\
\hline 4 & DC plate & 12.0 & 93.8 & 83.0 & 6.92 & Steel ISO 5832-1 \\
\hline 5 & $\mathrm{CD}$ rod & 6.0 & 50,3 & 26.5 & 4.42 & Steel ISO 5832-1 \\
\hline 6 & Fixed angle plate & 10.0 & 97.6 & 88.5 & 8.85 & Steel ISO 5832-1 \\
\hline 7 & Hip prosthesis cemented stem & 20.0 & 168.5 & 66.8 & 3.34 & Steel ISO 5832-9 \\
\hline 8 & Hip prosthesis cup & 28.3 & 24.7 & 90.0 & 3.18 & UHMWPE \\
\hline 9 & Spongious screw & 1.5 & 10.5 & 13.9 & 9.29 & Steel ISO 5832-1 \\
\hline 10 & Spongious screw & 1.5 & 4.7 & 40.7 & 27.13 & Ti6A14V ISO 5832-3 \\
\hline 11 & Hip prosthesis stem + head & 48.3 & 226.7 & 136.3 & 2.82 & $\begin{array}{l}\text { Ti6Al4V ISO 5832-3 } \\
\text { CoCrMo ISO 5832-4 }\end{array}$ \\
\hline 12 & Knee prothesis femoral component & 13.3 & 168.5 & 95.0 & 7.13 & CoCrMo ISO 5832-4 \\
\hline 13 & Hip prosthesis head & 9.3 & 66.5 & 30.7 & 3.29 & CoCrMo ISO 5832-4 \\
\hline 14 & Pedicular screw & 2.0 & 8.7 & 17.4 & 8.69 & Ti6A14V ISO 5832-3 \\
\hline
\end{tabular}

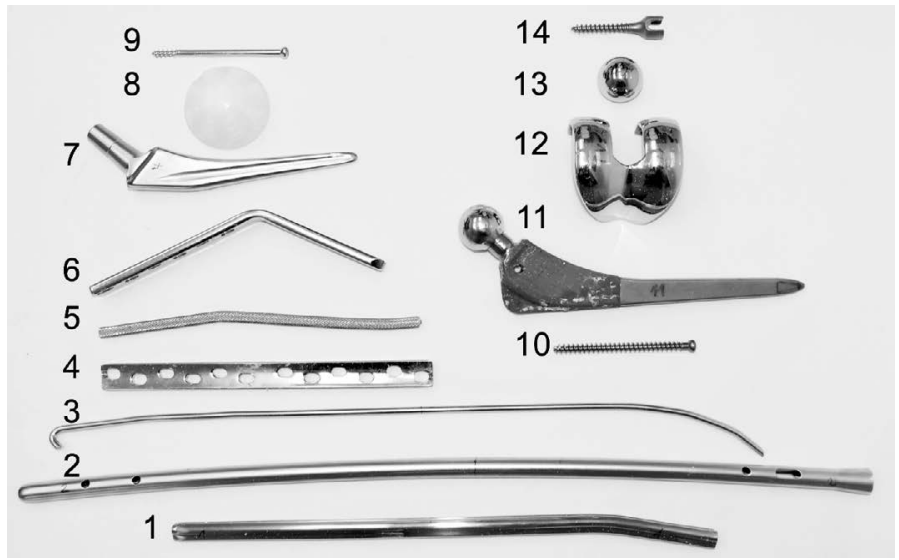

Figure 1. Implants included in the study. Thirteen metal Implants and one polyethylene cup was used as control
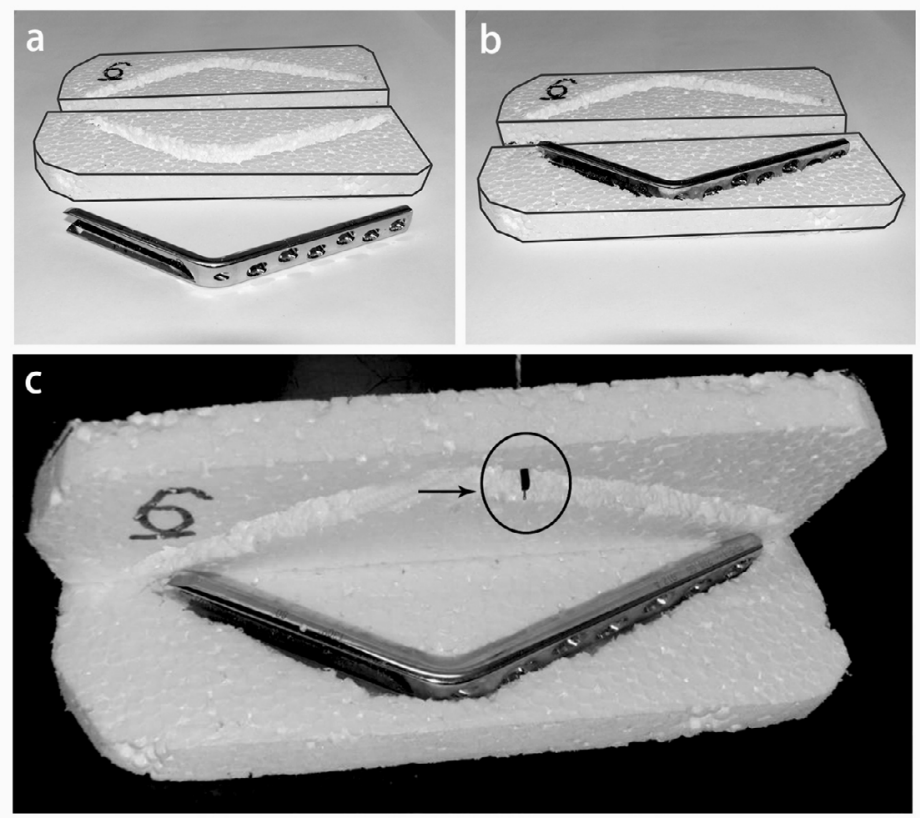

Figure 2. Implants surface temperature measurement. (a) Styrofoam top and bottom covers were carved to fit each implant; (b) Placing the implant into the bottom half of the cover; (c) Arrow showed the thermometer probe for temperature measurement 


\section{Statistical analysis}

Main outcome of this study is under dry and wet condition, the implants' temperature and position change in both 1.5T and 3T MR system. All statistical analyses were performed using SPSS software (version 21.0, SPSS Inc., Chicago, IL, USA).

\section{Results}

The pre- and post-scanning temperature of the implants at $1.5 \mathrm{~T}$ and 3.0 $\mathrm{T}$ in both dry and wet conditions are shown in Tables 2-3.

All temperature changes were $\leq 1^{\circ} \mathrm{C}$. All implants' temperature changed gradually close to the examination room temperature. No measurable displacement was observed in any case.

\section{Discussion}

MRI has been widely used in clinical practice for diagnosis and monitoring. As far as we know, there is still concern and misconception about the feasibility for patients with metal implants to take the exam, even among those professionals who are directly involved. The main reason is that metal implants' interaction with the static magnetic field could possibly produce heat and movement, causing harm to the patients. The artefacts could also substantially affect the diagnostic value of the MRI exam. Therefore, a lot of patients are precluded from the known advantages of MRI.

American Society for Testing and Materials (ASTM) has defined the concept of „MR-safe” for implants or devices which are used

Table 2. Temperature measurement results with 1.5-T equipment (room temperature: $24^{\circ} \mathrm{C}$ )

\begin{tabular}{|c|c|c|c|c|c|c|c|c|}
\hline \multirow{2}{*}{ Item No. } & \multicolumn{3}{|c|}{ Dry } & \multicolumn{3}{|c|}{ Wet } & \multirow{2}{*}{$\begin{array}{c}\text { Weight } \\
\text { (g) }\end{array}$} & \multirow{2}{*}{ Material } \\
\hline & Before & After & Difference & Before & After & Difference & & \\
\hline 1 & 24.0 & 24.0 & 0.0 & 24.0 & 23.9 & -0.1 & 102.3 & Steel ISO 5832-1 \\
\hline 2 & 24.0 & 24.0 & 0.0 & 24.0 & 24.2 & 0.2 & 191.1 & Steel ISO 5832-1 \\
\hline 3 & 24.3 & 23.9 & -0.4 & 23.9 & 23.9 & 0.0 & 55.6 & Steel ISO 5832-1 \\
\hline 4 & 23.7 & 24.0 & 0.3 & 24.0 & 23.9 & -0.1 & 93.8 & Steel ISO 5832-1 \\
\hline 5 & 23.9 & 24.0 & 0.1 & 24.0 & 24.0 & 0.0 & 50.3 & Steel ISO 5832-1 \\
\hline 6 & 24.0 & 24.2 & 0.2 & 24.2 & 23.7 & -0.5 & 97.6 & Steel ISO 5832-1 \\
\hline 7 & 22.9 & 23.4 & 0.5 & 23.4 & 24.0 & 0.6 & 168.5 & Steel ISO 5832-9 \\
\hline 8 & 23.7 & 24.3 & 0.6 & 24.3 & 24.3 & 0.0 & 24.7 & UHMWPE \\
\hline 9 & 24.3 & 24.1 & -0.2 & 24.1 & 24.0 & -0.1 & 10.5 & Steel ISO 5832-1 \\
\hline 10 & 23.8 & 24.0 & 0.2 & 24.0 & 24.0 & 0.0 & 4.7 & Ti6A14V ISO 5832-3 \\
\hline 11 & 23.3 & 23.5 & 0.2 & 23.5 & 24.0 & 0.5 & 226.7 & $\begin{array}{l}\text { Ti6Al4V ISO 5832-3 } \\
\text { CoCrMo ISO 5832-4 }\end{array}$ \\
\hline 12 & 22.6 & 23.6 & 1.0 & 23.6 & 23.8 & 0.2 & 168.5 & CoCrMo ISO 5832-4 \\
\hline 13 & 22.8 & 23.7 & 0.9 & 23.7 & 23.8 & 0.1 & 66.5 & CoCrMo ISO 5832-4 \\
\hline 14 & 24.2 & 23.8 & -0.4 & 23.8 & 23.9 & 0.1 & 8.7 & Ti6Al4V ISO 5832-3 \\
\hline Mean & 23.68 & 23.89 & 0.21 & 23.89 & 23.96 & 0.06 & & \\
\hline SD & 0.56 & 0.26 & 0.43 & 0.26 & 0.16 & 0.27 & & \\
\hline
\end{tabular}

Table 3. Temperature measurement results with 3.0-T equipment (room temperature: $19^{\circ} \mathrm{C}$ )

\begin{tabular}{|c|c|c|c|c|c|c|c|c|}
\hline \multirow{2}{*}{ Item No. } & \multicolumn{3}{|c|}{ Dry } & \multicolumn{3}{|c|}{ Wet } & \multirow{2}{*}{ Weight (g) } & \multirow{2}{*}{ Material } \\
\hline & Before & After & Difference & Before & After & Difference & & \\
\hline 1 & 19.5 & 19.4 & -0.1 & - & - & - & 102.3 & Steel ISO 5832-1 \\
\hline 2 & - & - & - & 18.2 & 17.8 & -0.4 & 191.1 & Steel ISO 5832-1 \\
\hline 3 & 18.8 & 19.0 & 0.2 & - & - & & 55.6 & Steel ISO 5832-1 \\
\hline 4 & 19.3 & 18.3 & -1.0 & 19.3 & 18.3 & -1.0 & 93.8 & Steel ISO 5832-1 \\
\hline 5 & 19.5 & 19.2 & -0.3 & 18.4 & 19.2 & 0.8 & 50.3 & Steel ISO 5832-1 \\
\hline 6 & 19.0 & 19.4 & 0.4 & - & - & - & 97.6 & Steel ISO 5832-1 \\
\hline 7 & - & - & - & 18.6 & 17.7 & -0.9 & 168.5 & Steel ISO 5832-9 \\
\hline 8 & 18.6 & 18.7 & 0.1 & - & - & - & 24.7 & UHMWPE \\
\hline 9 & - & - & - & 18.9 & 18.7 & -0.2 & 10.5 & Steel ISO 5832-1 \\
\hline 10 & 19.3 & 19.5 & 0.2 & - & - & - & 4.7 & Ti6Al4V ISO 5832-3 \\
\hline 11 & 18.8 & 19.5 & 0.7 & 18.7 & 18.9 & 0.2 & 226.7 & $\begin{array}{l}\text { Ti6Al4V ISO 5832-3 } \\
\text { CoCrMo ISO } 5832-4\end{array}$ \\
\hline 12 & 18.9 & 19.8 & 0.9 & - & - & - & 168.5 & CoCrMo ISO 5832-4 \\
\hline 13 & - & - & - & 20.5 & 19.6 & -0.9 & 66.5 & CoCrMo ISO 5832-4 \\
\hline 14 & 19.3 & 20.0 & 0.7 & - & - & - & 8.7 & Ti6Al4V ISO 5832-3 \\
\hline Mean & 19.09 & 19.28 & 0.24 & 18.94 & 18.60 & -0.34 & & \\
\hline SD & 0.31 & 0.51 & 0.63 & 0.77 & 0.71 & 0.67 & & \\
\hline
\end{tabular}


in the MR environment. It should not present additional risk to the patient, but may affect the quality of the diagnostic information [6]. In USA annually there are about hundreds of adverse events on MRI exam, but the skin surface contact or external metallic objects are the most common causes [7]. Because of the eddy currents in implants are parallel to the static magnetic field, theoretically radiofrequency heating is possible. However, until now there is still no confirm evidence in the literature that it's sever enough to cause tissue damage. Ex vivo studies have indicated that relatively small metal implants will not produce excessive heat or harm to patients during MR procedures, even when exposed to high levels of radiofrequency energy [8,9]. Feng even reported 39 medical implants at $7.0 \mathrm{~T}$ and the temperature change ranged from -0.5 to $0.41^{\circ} \mathrm{C}$ [10].

For MRI exam, higher the field strength, better the image quality. In our study, we compared each implant in both 1.5 - $\mathrm{T}$ system and 3.0-T system, also under dry and wet different humidity conditions. It more comprehensively proved that for orthopedic implants, prosthesis related heating or instability problem could be ignored. The higher or lower temperature differences observed during the study may be affected by the room temperature change, implant's material and weight, measurement error and other factors. Regarding the displacement, even for the smallest screw the magnetic field showed no effect on it. This is not surprising as the material for the implants are usually not magnetizable. Titanium is a paramagnetic material that is not affected by the magnetic field, but for the implants made of alloys, it's suggested necessary to further investigate different alloy proportion effect for the MR scanning [11].

Nowadays, a huge number of patients have accepted bone or joint surgeries and got different prostheses implanted inside. There are very high possibilities later in their lives they need MRI exams. Even though artefacts usually show up at the area near the implants, which can negatively affect the clinical evaluation, artefacts near the hip arthroplasty prosthesis will not interfere the lower lumbar assessment at all. Therefore, clinical decision making should base on each patient's specific situation. For example, for metal implant surgery it's not recommended immediate postoperative period undertaking MRI exam, and more attention should be paid on metal neurosurgical implants which close to brain or cerebral blood vessels.
In conclusion, based on our assessment on randomly selected orthopedic-traumatological implants, in terms of temperature and location, the MRI exam has no effect on either dry or wet implants at $1.5 \mathrm{~T}$ or $3 \mathrm{~T}$.

\section{Funding}

This research has been supported by the National Research Development and Innovation Office (NKFIH) through the OTKA Grant K125409.

\section{References}

1. Crouzier D, Selek L, Martz BA, Dabouis V, Arnaud R, Debouzy JC (2012) Risk assessment of electromagnetic fields exposure with metallic orthopedic implants: A cadaveric study. Orthopaedics \& Traumatology-Surgery \& Research 98(1):90-96. [Crossref]

2. Kumar R, Lerski RA, Gandy S, Clift BA, Abboud RJ (2006) Safety of orthopedic implants in magnetic resonance imaging: An experimental verification. Journal of Orthopaedic Research 24(9):1799-1802.

3. Shellock FG (2002) Biomedical implants and devices: Assessment of magnetic field interactions with a 3.0-Tesla MR system. Journal of Magnetic Resonance Imaging 16(6):721-732. [Crossref]

4. Shellock FG, Morisoli S, Kanal E (1993) Mr Procedures and Biomedical Implants, Materials, and Devices - 1993 Update. Radiology 189(2):587-599.

5. Várallyay G (2003) Fémek az MR-ben. Magyar Radiológia 77(2):62-67.

6. American Society for Testing and Materials. Designation: F 2052. Standard test method for measurement of magnetically induced displacement force on passive implants in the magnetic resonance environment. In: Annual book of ASTM standards, West Conshohocken, PA: (in press).

7. Delfino JG, Krainak DM, Flesher SA, Miller DL (2019) MRI-related FDA adverse event reports: A 10-yr review. Medical Physics 46(12):5562-5571. [Crossref]

8. Shellock FG (2001) Prosthetic heart valves and annuloplasty rings: Assessment of magnetic field interaction, heating, and artifacts at 1.5 Tesla. Journal of Cardiovascular Magnetic Resonance 3(4):317-324. [Crossref]

9. Shellock FG, Shellock VJ (1999) Metallic stents: Evaluation of MR imaging safety American Journal of Roentgenology 173(3):543-547. [Crossref]

10. Feng DX, Mccauley JP, Morgan-Curtis FK, Salam RA, Pennell DR, Loveless ME, Dula AN (2015) Evaluation of 39 medical implants at 7.0T. British Journal of Radiology 88(1056). [Crossref]

11. Kim YH, Choi M, Kim JW (2019) Are titanium implants actually safe for magnetic resonance imaging examinations? Archives of Plastic Surgery-Aps 46(1):96-97.

Copyright: (C2021 Csernátony Z. This is an open-access article distributed under the terms of the Creative Commons Attribution License, which permits unrestricted use, distribution, and reproduction in any medium, provided the original author and source are credited. 